\title{
Correction to: Effect of Packaging Materials and the Leached Iron on the Stability of Butorphanol Tartrate Injection
}

\author{
Zijun Dai, ${ }^{1}$ Chunmei Zhu, ${ }^{2}$ Jinyuan Lyu, ${ }^{2}$ Chunfeng Liu, ${ }^{2}$ Jiajian $\mathrm{Xu}^{2}{ }^{2}$ Haoxiang $\mathrm{Wu}^{2}{ }^{2}$ and Fuli Zhang ${ }^{1,2,3}$
}

published online 28 July 2021

Correction to: AAPS PharmSciTech volume 22, Article number: 186 (2021)

https://doi.org/10.1208/s12249-021-02060-4

In this article, Haoxiang $\mathrm{Wu}$ should have been denoted as a corresponding author.

Publisher's Note Springer Nature remains neutral with regard to jurisdictional claims in published maps and institutional affiliations.

The online version of the original article can be found at https:// doi.org/10.1208/s12249-021-02060-4

${ }^{1}$ Zhejiang University of Technology, No.18, Chaowang Road, Hangzhou, 310014, China.

${ }^{2}$ China State Institute of Pharmaceutical Industry, No.285, Copernicus Road, Shanghai, 201203, China.

${ }^{3}$ To whom correspondence should be addressed. (e-mail: zhangfuli1@sinopharm.com; austin163@163.com) 